Published in final edited form as:

Brain Struct Funct. 2017 May ; 222(4): 1913-1928. doi:10.1007/s00429-016-1315-9.

\title{
Organic cation transporter $\mathbf{3}$ (OCT3) is localized to intracellular and surface membranes in select glial and neuronal cells within the basolateral amygdaloid complex of both rats and mice
}

\author{
Paul J. Gasser ${ }^{1}$, Matthew M. Hurley ${ }^{1}$, June Chan ${ }^{2}$, and Virginia M. Pickel ${ }^{2}$ \\ ${ }^{1}$ Department of Biomedical Sciences, Marquette University, Milwaukee, WI 53201-1881, USA \\ ${ }^{2}$ Feil Family Brain and Mind Research Institute, Weill Cornell Medical College, 407 East 61st \\ Street, New York, NY 10065, USA
}

\begin{abstract}
Organic cation transporter 3 (OCT3) is a high-capacity, low-affinity transporter that mediates corticosterone-sensitive uptake of monoamines including norepinephrine, epinephrine, dopamine, histamine and serotonin. OCT3 is expressed widely throughout the amygdaloid complex and other brain regions where monoamines are key regulators of emotional behaviors affected by stress. However, assessing the contribution of OCT3 to the regulation of monoaminergic neurotransmission and monoamine-dependent regulation of behavior requires fundamental information about the subcellular distribution of OCT3 expression. We used immunofluorescence and immuno-electron microscopy to examine the cellular and subcellular distribution of the transporter in the basolateral amygdaloid complex of the rat and mouse brain. OCT3immunoreactivity was observed in both glial and neuronal perikarya in both rat and mouse amygdala. Electron microscopic immunolabeling revealed plasma membrane-associated OCT3 immunoreactivity on axonal, dendritic, and astrocytic processes adjacent to a variety of synapses, as well as on neuronal somata. In addition to plasma membrane sites, OCT3 immunolabeling was also observed associated with neuronal and glial endomembranes, including Golgi, mitochondrial and nuclear membranes. Particularly prominent labeling of the outer nuclear membrane was observed in neuronal, astrocytic, microglial and endothelial perikarya. The localization of OCT3 to neuronal and glial plasma membranes adjacent to synaptic sites is consistent with an important role for this transporter in regulating the amplitude, duration, and physical spread of released monoamines, while its localization to mitochondrial and outer nuclear membranes suggests previously undescribed roles for the transporter in the intracellular disposition of monoamines.
\end{abstract}

Correspondence to: Paul J. Gasser.

Compliance with ethical standards

Conflict of interest The authors declare no competing financial interests.

Research involving human participants and/or animals All applicable international, national, and/or institutional guidelines for the care and use of animals were followed. All procedures performed in studies involving animals were in accordance with the ethical standards of the institution or practice at which the studies were conducted. This article does not contain any studies with human participants performed by any of the authors. 


\section{Keywords}

Monoamine; Ultrastructure; Corticosterone; Serotonin; Norepinephrine; Dopamine; Histamine; Clearance; Uptake; Stress

\section{Introduction}

A critical step in the regulation of monoaminergic neurotransmission is the clearance of released transmitters from the extracellular space, limiting the duration and physical spread of monoamine signals, and thus determining the activation of receptors on target cells (Rice and Cragg 2008). Monoamine clearance has been attributed primarily to the high-affinity, $\mathrm{Na}^{+}$and $\mathrm{Cl}^{-}$-dependent norepinephrine transporter (NET), dopamine transporter (DAT) and serotonin transporter (SERT) (Jayanthi and Ramamoorthy 2005; Moron et al. 2002; Nemeroff and Owens 2004). However, recent studies have shown that organic cation transporter 3 (OCT3), also referred to as solute carrier family 22, member 3 (SLC22A3), which mediates the bidirectional, sodium-independent, low-affinity transport of all of the major monoamines (Grundemann et al. 1998, 1999; Schomig et al. 2006), is widely distributed in brain (Gasser et al. 2009; Vialou et al. 2004). While NET, DAT and SERT are plasmalemmal transporters expressed almost exclusively on central neurons, OCT3 is expressed in neurons, glia and ependymal cells (Cui et al. 2009; Graf et al. 2013; Vialou et al. 2004), suggesting that this transporter contributes to both neuronal and extraneuronal clearance of monoamines.

In contrast to transport mediated by NET, DAT and SERT, OCT3-mediated transport is insensitive to cocaine (Amphoux et al. 2006), and is much less sensitive to inhibition by antidepressants (Haenisch and Bonisch 2010). In addition, OCT3-mediated transport is directly and acutely inhibited by corticosterone and synthetic glucocorticoid hormones (Grundemann et al. 1998; Hill et al. 2011; Horvath et al. 2003; Horvath and Wanner 2003). Accumulating evidence indicates that OCT3-mediated transport influences extracellular concentrations of monoamines in vivo (Amphoux et al. 2006; Gasser et al. 2006; Vialou et al. 2008). We have demonstrated that OCT3-mediated transport in ex vivo brain tissue is inhibited by concentrations of corticosterone within the physiological stress range (Gasser et al. 2006; Hill et al. 2011), and that acute treatment of rats with corticosterone decreases the clearance of released dopamine and potentiates the neurochemical and behavioral effects of cocaine (Graf et al. 2013).

The expression of a stress hormone-sensitive mono-amine transporter may have particular relevance in limbic brain regions involved in the regulation of anxiety and fear. Indeed, mice genetically engineered to lack OCT3 expression exhibit altered levels of anxiety (Vialou et al. 2008; Wultsch et al. 2009). The amygdala, including the basolateral complex (BLAwhich includes lateral and basal amygdaloid nuclei) and associated nuclei, is particularly important in the regulation of anxiety responses, and amygdala function is modulated both by monoamines and glucocorticoids. We recently described the distribution of OCT3 immunoreactivity in the rat amygdala, with an emphasis on the intercalated cell clusters (Hill and Gasser 2013). However, the relevant subcellular sites for OCT3-mediated transport 
in the amygdala are largely unknown, and these are of direct relevance to neuronal as well as extraneuronal monoamine transport in this brain region (Inazu et al. 2003a). To fill this gap in our knowledge, we examined immunofluorescence and electron microscopic immunolabeling of OCT3 in the rodent BLA. Most studies of monoamine involvement in regulation of fear and anxiety through the lateral amygdala have been done in rats (Duvarci and Pare 2014), but mice are now increasingly used for this type of investigation.

Extrapolation from the extensive literature in rats for interpretation of the results in mice is highly problematic because of interspecies differences in their behavioral and biogenic amine responses to stress (Konstandi et al. 2000; Asan et al. 2005). Thus, we examined the cellular and subcellular distribution of OCT3 in both rats and mice to determine potential species differences in the targeting of OCT3 in this brain region.

\section{Materials and methods}

Adult male Sprague-Dawley rats (Harlan Laboratories, Inc., St Louis, MO) and C57BL/6 J mice (Jackson Laboratory, Bar Harbor, ME) were used for the microscopic analysis of OCT3 localization. Experimental procedures were carried out in accordance with the National Institutes of Health Guidelines for the Care and Use of Laboratory Animals (NIH publication number 80-23, revised 1996), and approved by the institutional animal care and use committees (IACUC) at Marquette University and Weill Medical College of Cornell University.

\section{Brain fixation and sectioning}

Light microscopy-The animals were deeply anesthetized by intraperitoneal injection of sodium pentobarbital $(50 \mathrm{mg} / \mathrm{kg}$ ) and were transcardially perfused with $0.05 \mathrm{M}$ phosphatebuffered saline (PBS) followed by $4 \%$ paraformaldehyde in $0.1 \mathrm{M}$ sodium phosphate buffer ( $\mathrm{PB}, \mathrm{pH}$ 7.4). Following perfusion, brains were removed and post-fixed in $4 \%$ paraformaldehyde solution for $12 \mathrm{~h}$ at $4{ }^{\circ} \mathrm{C}$, and were rinsed twice in $0.1 \mathrm{M} \mathrm{PB}$ for $12 \mathrm{~h}$. The brains were incubated in $30 \%$ sucrose in $0.1 \mathrm{M} \mathrm{PB}$ at $4{ }^{\circ} \mathrm{C}$ for approximately $72 \mathrm{~h}$. Brains were then blocked into two pieces with a cut in the coronal plane at the caudal border of the mammillary bodies (approximately $-5.30 \mathrm{~mm}$ bregma) using a rat brain matrix (RBM-4000C, ASI Instruments, Warren, MI, USA). The brain tissue was then frozen rapidly in dry-ice-chilled liquid isopentane and stored at $-80{ }^{\circ} \mathrm{C}$ until sectioning. Forebrain sections $(25 \mu \mathrm{m})$ including the basolateral amygdala were cut across the coronal plane using a cryostat (Leica Biosystems, Buffalo Grove, IL, USA), and stored as 6 alternate sets of sections in cryoprotectant [30\% ethylene glycol (w/w)/20\% glycerol (w/w) in 0.05 M PB, $\mathrm{pH} 7.4]$ at $-20{ }^{\circ} \mathrm{C}$ until immunostaining.

Electron microscopy-Anesthetized rats were perfused through the ascending aorta with (1) $20 \mathrm{ml}$ of heparin $(1000 \mathrm{U} / \mathrm{ml}$ ) in saline, (2) $50 \mathrm{ml}$ of $3.8 \%$ acrolein (Polysciences, Warrington, PA, USA) in a solution of $2 \%$ paraformaldehyde in $0.1 \mathrm{M}$ phosphate buffer (PB), and (3) $200 \mathrm{ml}$ of $2 \%$ paraformaldehyde in $0.1 \mathrm{M} \mathrm{PB}$. Ventricular perfusions in mice employed these same solutions at volumes of (1) 15, (2) 40 and (3) $100 \mathrm{ml}$, respectively. The aldehyde-fixed brains were then removed from the cranium and placed in $2 \%$ paraformaldehyde in PB for 30 min prior to sectioning on a Leica Vibratome (Leica 
Microsystems, Bannockburn, IL, USA). Coronal sections of $40 \mu \mathrm{m}$ were collected through the rostrocaudal extent of the amygdala as defined in a rat (Franklin and Paxinos 1997; Paxinos and Watson 1998).

\section{Antibodies}

For immunodetection of OCT3, an affinity-isolated antibody (rabbit anti-OCT3, cat \# OCT31A, Alpha Diagnostics International, San Antonio, TX, USA) raised against an 18amino acid sequence in the large intracellular loop of rat OCT3 (amino acids 313-330: HLSSNY-SEITVTDEEVSN) was used at a dilution of 1:250 for light microscopic immunolabeling. This amino acid sequence is $100 \%$ conserved in mouse and rat OCT3, and has no significant sequence homology with other OCTs or with any organic cation/carnitine transporters. The specificity of this antibody was confirmed previously in immunoperoxidase and immunofluorescence applications (Gasser et al. 2006, 2009; Lips et al. 2005; Vialou et al. 2004). For immunodetection of neuron-specific Beta-III tubulin, a monoclonal antibody (mouse anti-beta-III Tubulin, cat\# ab7751, Abcam, Cambridge, MA, USA) was used at a dilution of 1:1200. For immunodetection of glial fibrillary acidic protein (GFAP), a monoclonal antibody (mouse anti-GFAP, cat\# MAB360, EMD Millipore, Billerica, MA, USA) was used at a dilution of 1:3000.

\section{Immunofluorescence}

Separate coronal sections $(25 \mu \mathrm{m})$ containing the BLA were used for combined detection of OCT3 and either GFAP or beta-III tubulin. After rinsing in $0.05 \mathrm{M}$ PBS, sections were incubated with $0.05 \mathrm{M}$ PBS containing $0.3 \%$ Triton X-100, $5 \%$ normal donkey serum, and $0.3 \mathrm{M}$ glycine. After additional rinses in $0.05 \mathrm{M}$ PBS, sections were incubated for $14-16 \mathrm{~h}$ at room temperature with primary antibodies diluted in PBS containing $0.1 \%$ Triton X-100 and $5 \%$ normal donkey serum. Sections were rinsed the next day, and incubated for $2 \mathrm{~h}$ with fluorophore-conjugated secondary antibodies [AlexaFluor594-conjugated donkey anti-rabbit and AlexaFluor488-conjugated donkey anti-mouse IgG antibodies (1:500; Invitrogen)]. Sections were then rinsed briefly in $0.1 \mathrm{M}$ sodium phosphate buffer, mounted onto SuperFrost microscope slides, dried briefly and coverslipped with Vectashield antifade mounting medium containing DAPI for visualization of nuclei (Vector Laboratories). All immunostaining studies were repeated a minimum of three times with similar results.

Photomicrographs were acquired using a Nikon 80i microscope fitted with a Retiga 2000R digital camera (QImaging, Surrey, BC, Canada) linked to a computer running NIS ElementsD software (Nikon Instruments, Melville, NY, USA). Color bright field images were captured using a liquid crystal RGB color filter (QImaging RGB-HM-S-IR).

\section{Electron microscopic immunolabeling and data analysis-Brain sections were} incubated for $30 \mathrm{~min}$ in a solution of $1 \%$ sodium borohydride in $0.1 \mathrm{M} \mathrm{PB}$ to remove excess active aldehydes prior to processing for immunoperoxidase or immunogold-silver labeling.

For immunoperoxidase labeling, prepared sections of aldehyde-fixed tissue were incubated overnight at room temperature in a 1:400 dilution of a rabbit antiserum against OCT3, which was prepared in Tris-saline containing $0.1 \%$ bovine serum albumin (BSA). The source and 
characterization of the antiserum are described in the section on light microscopy. Sections were then washed in PB and incubated for $30 \mathrm{~min}$ in biotinylated donkey anti-rabbit immunoglobulin (IgG, 1:200) (Jackson ImmunoResearch Laboratories, West Grove, PA, USA). These sections were then incubated for $30 \mathrm{~min}$ in Vectastain ABC Elite kit (Vector Laboratories, Burlingame, CA). The product was visualized by reaction in $3,3^{\prime}$ diaminobenzadine (DAB, Sigma-Aldrich, St. Louis, MO) and hydrogen peroxide.

For immunogold-silver labeling, tissue sections prepared as described above were incubated overnight at room temperature in the primary OCT3 antibody at 1:400 dilution, then transferred to $0.01 \mathrm{M}$ PBS. The sections were then blocked for $10 \mathrm{~min}$ in $0.8 \% \mathrm{BSA}$ and $0.1 \%$ gelatin in $0.01 \mathrm{M}$ PBS, and incubated for $2 \mathrm{~h}$ in ultrasmall colloidal gold-labeled goat anti-rabbit IgG, [1:50; Electron Microscopic Sciences (EMS; Fort Washington, PA)]. After this incubation, the sections were fixed for $10 \mathrm{~min}$ in $2 \%$ glutaraldehyde in $0.01 \mathrm{M}$ PBS to enhance the adherence of the bound gold to the tissue, and reacted with a silver solution IntenSE ${ }^{\mathrm{TM} M}$ kit (Amersham, Arlington Heights, IL) for 4-6 min.

The immunoperoxidase- and immunogold-labeled sections of tissue were post-fixed in $2 \%$ osmium tetroxide in $0.1 \mathrm{M} \mathrm{PB}$ for $1 \mathrm{~h}$, followed by washing and dehydration through a graded series of ethanol followed by propylene oxide. The sections were incubated overnight in a 1:1 mixture of propylene oxide and Epon (Embed 812) (EMS), and then placed in $100 \%$ Epon for $2 \mathrm{~h}$ prior to flat-embedding between two sheets of Aclar plastic. Ultrathin sections through the BLA were cut from the surface of the tissue using a Leica ultramicrotome (Leica Microsystems, Bannockburn, IL). Ultrathin sections were placed on grids and counterstained with uranyl acetate and lead citrate. An FEI Tecnai electron microscope (FEI, Hillsboro, OR) was used for examining sections and capturing digital images. In these images, immunoperoxidase labeling was considered to be positive when an electron-dense precipitate was seen in selective profiles but absent in adjacent profiles having otherwise similar morphology. Immunolabeled structures were separated into categories of dendrites (dendritic shafts and spines), axon terminals, small neuronal profiles (mainly unmyelinated axons and spine necks) or glial processes, using the nomenclature of Peters et al. (1991). Figures were prepared from the acquired digital images by initial adjustment of contrast and brightness using Adobe Photoshop CS4 and Adobe Illustrator CS6.

\section{Results}

\section{Immunofluorescence}

OCT3 immunoreactive perikarya and punctae were observed throughout the BLA in both rat (Fig. 1a) and mouse (Fig. 2a), with high density in the intercalated cell groups. In the BLA, OCT3 immunoreactivity was observed in subsets of GFAP-positive (Fig. 1), $\beta$-III tubulinpositive (rat, Fig. 2a-c), and NeuN-positive (mouse, Fig. 2d-f) cell bodies. Intense perinuclear OCT3 immunofluorescence signal was observed in most GFAP-positive cells (Fig. 1). This signal completely overlapped the DAPI-stained nuclei, and was most intense in a rim around the nucleus (Fig. 1c-h). OCT3-immunoreactive punctae were also observed overlapping or immediately adjacent to GFAP-immunoreactive processes (Fig. 1c, d, f, g). Perinuclear OCT3-immunoreactivity was also observed in subsets of GFAP-negative (Fig. 
1b), $\beta$-III tubulin-positive (Fig. 2b, c), and NeuN-positive (Fig. 2e, f) cell bodies, but the perinuclear staining in these cells was generally less intense than that observed in GFAPpositive cells. In $\beta$-III tubulin-positive cell bodies, $\beta$-III tubulin immunoreactivity was observed in perikarya and fine processes, and was absent from the nucleus (Fig. 2c). In these cell bodies, OCT3-immunoreactive punctae were observed both over nuclei and over $\beta$-III tubulin-positive processes. In NeuN-positive cells, intense NeuN immunoreactivity was observed in nuclei, with less intense immunoreactivity in the cytoplasm. In these cells, OCT3-immunoreactivity was most intense in a rim around the nucleus, but less intense, punctate immunoreactivity was also observed over the cytoplasm.

\section{Electron microscopic localization of ОСТ3 in glial and neuronal processes}

OCT3 was varyingly localized in glial and neuronal (dendritic and axonal) processes in the BLA of both rat and mouse (Table 1). In glial processes, the OCT3 immunoperoxidase was most prevalent along the plasma membrane, but also was distributed diffusely around, or associated with, endomembranes within cytoplasmic compartments (Fig. 3). OCT3immunoreactive glial processes were frequently observed in close proximity to asymmetric axodendritic (Fig. 3a) and axospinous synapses (Fig. 3b). OCT3 immunoreactivity was also seen in filamentous glial processes in contact with unlabeled axon terminals without recognizable synaptic specializations (Fig. 3c) or with small unlabeled axons (Fig. 3d).

OCT3-labeled dendritic profiles (dendritic shafts and spines) comprise approximately $25 \%$ of the immunoreactive processes in the BLA (Table 1). In dendritic shafts, the OCT3 immunoperoxidase reaction product was intensely localized to cytoplasmic endomembranes (Fig. 4a), and to transitional zones between mitochondrial and plasma membranes that also appeared to express OCT3-immunoreactivity (Fig. 4c). In these dendrites, the plasmalemmal immunoreactivity was partially obscured by the intense cytoplasmic labeling. However, in small dendrites (Fig. 4b) and dendritic spines (Figs. 3b, 4b, c, f, 5f-h), OCT3

immunoperoxidase reaction product was clearly evident along the postsynaptic membranes. Immunogold labeling revealed OCT3 immunoreactivity distinctly localized to dendritic plasma membranes (Fig. 4d) and mitochondrial surfaces (Fig. 4e).

Axonal profiles (axons and axon terminals) comprised the greatest percentage of all OCT3labeled processes in the BLA neuropil (Table 1). Many unmyelinated as well as a few myelinated axons contained aggregates of OCT3 immunoreactivity associated with vesiclelike endomembranes (Fig. 5a). The OCT3 immunoperoxidase labeling also was frequently localized to clusters of small vesicles in axon terminals forming symmetric synapses with neuronal somata (Fig. 5b) and dendrites (Fig. 5c). In these axon terminals, OCT3 immunoreactivity was faintly seen along portions of the plasma membrane contacted by opposing axons that were unlabeled and usually without recognizable synaptic junctions within the plane of section. Other similarly non-synaptic terminals were opposed to unlabeled dendrites (Fig. 5d) and dendritic spines (Fig. 5e), and these terminals showed intense OCT3 labeling on membranes of large vesicles. The labeled terminals in contact with dendritic spines were interposed at asymmetric excitatory-type synapses, a site known to be occupied by dopamine axons (Pinto and Sesack 2008; Muller et al. 2009; Pinard et al. 2010). OCT3-immunoreactivity was also localized to isolated vesicles and/or presynaptic 
membranes in axon terminals forming asymmetric synapses with dendritic spines (Fig. 5fh).

\section{Electron microscopic localization of ОСТ3 in non-neuronal cell bodies-}

Electron microscopy confirmed the localization of OCT3 immunoreactivity in perikarya of astrocytic glial cells in the BLA, and further demonstrated the presence of OCT3 labeling in non-astrocytic glial cells as well as in endothelial cells in the BLA of both rat and mouse (Fig. 6). The astrocytic perikarya were morphologically distinguished from oligodendrocytes and microglia by their enrichment in bundles of intermediate filaments and large round nuclei lacking the dense rim of chromatin commonly seen in the non-astrocytic glia (Peters et al. 1991). In all glial cells, the OCT3 immunoreactivity was intensively and unevenly localized to the outer nuclear membrane and associated perinuclear cytoplasm (Fig. 6). Aggregates of peroxidase reaction product were often seen on the cytoplasmic surface of the nuclear membrane opposed to mitochondria or endomembranes in the region of the Golgi cisternae (Fig. 6a, d). Other cytoplasmic compartments of glial cells were largely without OCT3 immunoreactivity except in regions where there was proximity between the nuclear membranes and plasma membranes showing an irregular contour encasing nearby axonal or dendritic profiles (Fig. 6a). These neuronal profiles included axon terminals forming asymmetric excitatory-type synapses. Non-astrocytic glial cells containing OCT3 immunoreactivity were frequently located near small capillaries and arterioles of blood vessels and myelinated axons (Fig. 6b-d). Capillary endothelial cells showed intense cytoplasmic labeling for OCT3 on the luminal and abluminal surface contacted by unlabeled astrocytic end feet on the blood vessel (Fig. 6b).

\section{Electron microscopic OCT3 localization in neuronal somata-Electron} microscopy showed intense OCT3 immunoperoxidase labeling and more sparse immunogold labeling of nuclear membranes in neuronal somata (Figs. 7, 8). The nuclear membranes were associated with round and unindented (Fig. 7a), or heavily indented nuclei (Fig. 7b), which are typical of pyramidal cells and interneurons, respectively, in the BLA of both rat and mouse. The most prominent labeling of nuclear membranes was seen in regions near the Golgi apparatus, where there appeared to be continuity between the nuclear envelope and trans-Golgi cisternae (Fig. 7b). In addition, however, the OCT3immunoreactivity was localized to discrete segments of the plasma membrane and associated membrane cisternae in somata (Figs. 7d, 8a). The somata containing OCT3 received many symmetric, inhibitory-type synapses from axon terminals with or without detectable OCT3 immunoreactivity. These cells were also in direct contact with nonsynaptic surfaces of axon terminals forming asymmetric excitatory-type synapses typical of glutamatergic neurons (Fig. 7b). In addition, the plasmalemmal and endomembrane OCT3 immunoreactivity was sometimes seen on surfaces opposed by unlabeled glial profiles (Fig. 7d). The labeled endomembranes were contiguous with a cytoplasmic network of membranes extending from the plasma to nuclear membranes (Fig. 7a).

\section{Discussion}

This study is the first to examine the subcellular localization of OCT3 in any tissue, and the first to explore its spatial relationship to synaptic structures in the brain. Consistent with 
previous studies, our immunofluorescence studies demonstrated OCT3 expression in both neurons and astrocytic glial cells (Cui et al. 2009; Inazu et al. 2003a; Takeda et al. 2002; Yoshikawa et al. 2013). The electron microscopic immunolabeling provides new evidence for the selective plasmalemmal and cytoplasmic localization of OCT3 immunoreactivity in glial, and both pre- and post-synaptic neuronal, processes in the BLA. This labeling also shows substantial localization of OCT3 to nuclear membranes and endomembrane systems, including vesicular structures and mitochondria, in both neuronal and glial perikarya. Together, these findings further our understanding of the cellular sites and mechanisms involved in the high-capacity, corticosterone-sensitive monoamine transport mediated by OCT3. They suggest that OCT3 not only contributes to the clearance of extracellular monoamines, but also plays a role in their intracellular disposition and action.

\section{Methodological considerations}

The observed light and electron microscopic distributions of OCT3 immunoreactivity in both species was similar using multiple labeling methods which differ in their sensitivity and resolution. Immunoperoxidase is the primary method of choice for our ultrastructural analysis because of its greater sensitivity when compared with immunogold methods. Though the peroxidase reaction product is diffuse, and thus limits the accuracy with which subcellular localization can be attributed, the greater sensitivity of this method allows a more complete assessment of the cellular and subcellular sites of enrichment. Profiles were considered immunolabeled when they contained one or more gold particles or a peroxidase reaction product with an electron density greater than that seen in nearby profiles. The validity of considering small profiles with only one immunogold particle as specifically labeled has been established for other neurotransmitter receptors (Garzon and Pickel 2006; Hara et al. 2006). However, the method is dependent on first establishing that there are a minimal number of particles overlying myelin and other tissue elements not known to express the antigen of interest (Wang et al. 2003). In the present study, this criterion was met for the immunogold labeling of OCT3. However, the low density of immunogold particles may have resulted in many false negatives and an underestimation of the number of neuronal and glial profiles that express OCT3. To minimize the false-negative data resulting from inadequate penetration of immunoreagents, electron microscopic images were collected exclusively from the tissue-plastic interface in sections subjected to a rapid freeze-thaw cycle prior to immunolabeling to enhance penetration. With these precautions, the immunoperoxidase and immuno-gold-silver methods used in our study showed a remarkably similar distribution of OCT3 at sites of greatest abundance such as the outer nuclear and mitochondrial membranes.

\section{OCT3 is localized to plasma membranes of glial processes, axonal and dendritic profiles, and neuronal somata}

The localization of OCT3 to plasma membranes of both neurons and glia is consistent with previous studies demonstrating expression of the transporter in astrocytes (Cui et al. 2009) and neurons (Graf et al. 2013; Hill and Gasser 2013; Vialou et al. 2004), and with its previously described role as a transporter mediating the uptake of extracellular monoamines (Grundemann et al. 1998). The results provide new insight into the sites at which the transporter may mediate the uptake of monoamines and other substrates. They suggest the 
intriguing possibility that OCT3 can contribute to the clearance of extracellular monoamines by pre- and postsynaptic neurons, and by astrocytic and non-astrocytic glia. The findings are consistent with an important role of the transporter in regulating the amplitude, duration, and physical spread of extracellular monoamines in the amygdala.

Axonal profiles-The prevalence of OCT3-immunolabeling on axons, compared with dendritic or glial profiles, suggests important roles for OCT3 in presynaptic mechanisms that may include the homo- and/or hetero-synaptic uptake and clearance of monoamines in the BLA. The prominent OCT3 labeling in many small unmyelinated axons and axon-terminals that were either without recognizable synapses or formed either symmetric or asymmetric synapses is consistent with the known extrinsic sources and diverse morphology of the monoaminergic innervation in the BLA ( $\mathrm{Li}$ et al. 2002). Many of these terminals contained loosely packed small clear and large dense core vesicles, features shared by many noradrenergic terminals (Asan 1998; Li et al. 2002). In addition, the membranes of these vesicles were often rimmed with OCT3 immunoreactivity, a pattern similar to that reported for NET immunoreactivity in noradrenergic terminals in the amygdala (Zhang et al. 2013). Together, these observations suggest that presynaptic reuptake mechanisms include both high-affinity, low-capacity, NET-mediated, and low-affinity, high-capacity, OCT3-mediated components.

OCT3-immunoreactivity was also observed in axon terminals containing densely packed small clear vesicles, which often formed symmetric synapses typical of parvalbumincontaining GABAergic interneurons on adjacent somata (Muller et al. 2006). Another group of OCT3-labeled axon terminals with densely packed vesicles formed asymmetric synapses on spine heads, which are typical of glutamatergic terminals in the BLA (Gan et al. 2014). Previous studies have demonstrated that monoamines exert potent modulatory influence over both GABAergic (Chu et al. 2012; Jiang et al. 2005, 2009), and glutamatergic (Ferry et al. 1997; Jiang et al. 2005; Rosenkranz and Grace 2002) neurotransmission in this region. Thus, depending on the identity of OCT3-expressing terminals, OCT3-mediated clearance may regulate the extent to which these monoamines can modulate GABAergic or glutamatergic neurotransmission.

Dendritic profiles-OCT3 immunoreactivity was also observed in neuronal somata and dendrites, many of which had the morphological features of pyramidal cells, the primary targets of dopaminergic inputs in the BLA (Muller et al. 2009). These neurons are among those that receive dopaminergic input on their smaller distal dendrites (Muller et al. 2009). However, other OCT3-labeled somatodendritic profiles showed morphological features of inhibitory interneurons, some of which are known recipients of both dopamine (Pinard et al. 2008) and serotonin inputs in this brain region (McDonald and Mascagni 2007), and which provide numerous inhibitory-type synapses on somata of pyramidal neurons in the corticallike BLA (Muller et al. 2006). These observations are consistent with a role for OCT3 in regulating monoaminergic influences over excitatory and inhibitory neurotransmission in the BLA.

Glial processes-The localization of OCT3 immunoreactivity to astrocytic processes is consistent with previous studies demonstrating OCT3 expression and function in rat and 
human astrocytes in vivo and in culture (Cui et al. 2009; Inazu et al. 2003a; Streich et al. 1996). The glial distribution of OCT3 and known glial expression of SERT and NET (Inazu et al. 2001, 2003b) suggest that monoamine clearance by brain astrocytes consists of Uptake $_{1}$ - and Uptake ${ }_{2}$-mediated components. The observation that OCT3-expressing glial processes ensheathe axospinous and axodendritic synapses further suggests involvement of the transporter in regulating monoamine signaling at these sites. Understanding the precise role of OCT3 in regulating monoaminergic neurotransmission in these areas will require additional studies examining the localization of OCT3 with respect to monoamine receptors and other transporters.

\section{OCT3 is highly expressed on nuclear membranes of astrocytic glia and morphologically diverse neurons in the BLA}

OCT3 immunoreactivity was densely distributed along outer portions of nuclear membranes in many neurons and glial cells. Some nuclear membrane labeling likely represents OCT3 not yet trafficked to plasma membrane sites where it will ultimately function. However, the dense labeling of the nuclear membrane, coupled with the paucity of endoplasmic reticulum and Golgi labeling in most cells, suggests that the nuclear membrane is also a functional site for the transporter, and that OCT3 may be actively involved in the transport of monoamines into or out of the lumen of the nuclear envelope. Consistent with this possibility, serotonin (Csaba and Kovacs 2006) and norepinephrine (Buu et al. 1993) have previously been detected in the nuclear compartment, and adrenergic receptor binding (Buu et al. 1993) and immunostaining (Aoki et al. 1989) have been localized to nuclear membranes. Indeed, recent studies have demonstrated that functional adrenergic receptors are localized to inner nuclear membranes of cardiomyocytes, and that norepinephrine gains access to these receptors via OCT3-mediated transport across the outer nuclear membrane (Dahl et al. 2015; Wu et al. 2014; Wu and O'Connell 2015). Thus, in some neurons and astrocytes, nuclear membrane-localized OCT3 may gate ligand access to monoamine receptors localized to the inner nuclear membrane, allowing activation of associated signal transduction cascades. Alternatively, OCT3 may gate the access of monoamine substrates to metabolic enzymes, including monoamine oxidase (MAO) and catechol-O-methyltransferase (COMT), both of which have been identified in glial and neuronal nuclear envelopes (Muller and Da 1977; Myohanen et al. 2010; Ulmanen et al. 1997).

\section{OCT3 is localized to somatodendritic plasma membranes, endomembranes, and mitochondrial membranes in BLA neurons}

The presence of OCT3 immunoreactivity along mitochondrial membranes in somata and dendrites is consistent with involvement of the transporter in neuronal and extraneuronal uptake and metabolism of monoamines by mitochondrial MAO and/or COMT (Trendelenburg 1990). OCT3 co-distributes with MAO in peripheral tissues (Verhaagh et al. 2001), and COMT is also highly expressed in postsynaptic dendrites and dendritic spines (Karhunen et al. 1995), which were the major OCT3-labeled dendritic profiles in the present study. OCT3-immunoreactive mitochondria were often opposed to postsynaptic membranes that were also densely labeled for OCT3, suggesting a cellular substrate conducive to membrane transport and rapid mitochondrial metabolism of monoamines in postsynaptic dendrites. 


\section{Implications}

The results from the present study provide new insights into potential roles of OCT3 in regulating both the extracellular concentrations of monoamines and their intracellular disposition and/or function. Plasmalemmal OCT3 is positioned to influence extracellular monoamine concentrations and, therefore, monoaminergic regulation of neuronal function, at a variety of locations, including astrocytic and pre- and postsynaptic processes. In addition, OCT3 localized to endomembranes, including mitochondrial and nuclear membranes, is positioned to play key roles in the regulation of monoamine metabolism and may regulate the activation of intracellular monoamine receptors. Because of its sensitivity to acute inhibition by corticosteroids, including cortisol and corticosterone, monoamine transport mediated by OCT3 would be decreased during acute or chronic stress, leading to increases in the duration, concentration, and physical spread of monoamine signals. This phenomenon may underlie some of the documented interactions between corticosterone and monoamines including serotonin (Stutzmann et al. 1998), dopamine (Graf et al. 2013), and norepinephrine (McReynolds et al. 2010; Roozendaal et al. 2004a, b).

OCT3 is expressed widely throughout the brain (Gasser et al. 2009; Vialou et al. 2004). The results of the present studies show that OCT3 is strategically positioned for involvement in regulation of monoaminergic neurotransmission in the amygdala. The localization of a corticosterone-sensitive monoamine transporter on axonal, dendritic and astrocytic plasma membranes raises interesting questions about the effects of acute and chronic stress on monoaminergic neurotransmission and the regulation of behaviors including anxiety and emotional learning and memory. The localization of the transporter to intracellular membranes, particularly nuclear and mitochondrial membranes, suggests that OCT3 plays a role in previously undescribed processes involved in monoamine metabolism and intracellular signaling. Future studies examining the proximity of OCT3 to monoamine receptors, metabolizing enzymes, and other transporters will clarify the roles of this transporter in regulating monoamine signaling, brain function, and behavior.

\section{Acknowledgments}

Supported by Grants: National Institute on Drug Abuse (DA032895) to PJG; National Institute of Mental Health (MH40342), National Institutes of Health (HL09657) and National Institute on Drug Abuse (DA04600 and DA005130) to VMP.

\section{References}

Amphoux A, Vialou V, Drescher E, Bruss M, La Cour CM, Rochat C, Millan MJ, Giros B, Bonisch H, Gautron S. Differential pharmacological in vitro properties of organic cation transporters and regional distribution in rat brain. Neuropharmacology. 2006; 50:941-952. [PubMed: 16581093]

Aoki C, Zemcik BA, Strader CD, Pickel VM. Cytoplasmic loop of beta-adrenergic receptors: synaptic and intracellular localization and relation to catecholaminergic neurons in the nuclei of the solitary tracts. Brain Res. 1989; 493:331-347. [PubMed: 2569914]

Asan E. The catecholaminergic innervation of the rat amygdala. Adv Anat Embryol Cell Biol. 1998; 142:1-118. [PubMed: 9586282]

Asan E, Yilmazer-Hanke DM, Eliava M, Hantsch M, Lesch KP, Schmitt A. The corticotropin-releasing factor (CRF)-system and monoaminergic afferents in the central amygdala: investigations in different mouse strains and comparison with the rat. Neuroscience. 2005; 131:953-967. [PubMed: 15749348] 
Buu NT, Hui R, Falardeau P. Norepinephrine in neonatal rat ventricular myocytes: association with the cell nucleus and binding to nuclear alpha 1- and beta-adrenergic receptors. J Mol Cell Cardiol. 1993; 25:1037-1046. [PubMed: 8283467]

Chu HY, Ito W, Li J, Morozov A. Target-specific suppression of GABA release from parvalbumin interneurons in the basolateral amygdala by dopamine. J Neurosci. 2012; 32:14815-14820. [PubMed: 23077066]

Csaba G, Kovacs P. Perinuclear localization of biogenic amines (serotonin and histamine) in rat immune cells. Cell Biol Int. 2006; 30:861-865. [PubMed: 16901725]

Cui M, Aras R, Christian WV, Rappold PM, Hatwar M, Panza J, Jackson-Lewis V, Javitch JA, Ballatori N, Przedborski S, Tieu K. The organic cation transporter-3 is a pivotal modulator of neurodegeneration in the nigrostriatal dopaminergic pathway. Proc Natl Acad Sci U S A. 2009; 106:8043-8048. [PubMed: 19416912]

Dahl EF, Wright CD, O’Connell TD. Quantification of catecholamine uptake in adult cardiac myocytes. Methods Mol Biol. 2015; 1234:43-52. [PubMed: 25304347]

Duvarci S, Pare D. Amygdala microcircuits controlling learned fear. Neuron. 2014; 82(5):966-980. [PubMed: 24908482]

Ferry B, Magistretti PJ, Pralong E. Noradrenaline modulates glutamate-mediated neurotransmission in the rat basolateral amygdala in vitro. Eur J Neurosci. 1997; 9:1356-1364. [PubMed: 9240393]

Franklin, KBJ., Paxinos, G. The Mouse Brain in Stereotaxic Coordinates. San Diego: Academic Press; 1997.

Gan JO, Bowline E, Lourenco FS, Pickel VM. Adolescent social isolation enhances the plasmalemmal density of NMDA NR1 subunits in dendritic spines of principal neurons in the basolateral amygdala of adult mice. Neuroscience. 2014; 258:174-183. [PubMed: 24231734]

Garzon M, Pickel VM. Subcellular distribution of M2 muscarinic receptors in relation to dopaminergic neurons of the rat ventral tegmental area. J Comp Neurol. 2006; 498:821-839. [PubMed: 16927256]

Gasser PJ, Lowry CA, Orchinik M. Corticosterone-sensitive monoamine transport in the rat dorsomedial hypothalamus: potential role for organic cation transporter 3 in stress-induced modulation of monoaminergic neurotransmission. J Neurosci. 2006; 26:8758-8766. [PubMed: 16928864]

Gasser PJ, Orchinik M, Raju I, Lowry CA. Distribution of organic cation transporter 3, a corticosterone-sensitive monoamine transporter, in the rat brain. J Comp Neurol. 2009; 512:529555. [PubMed: 19025979]

Graf EN, Wheeler RA, Baker DA, Ebben AL, Hill JE, McReynolds JR, Robble MA, Vranjkovic O, Wheeler DS, Mantsch JR, Gasser PJ. Corticosterone acts in the nucleus accumbens to enhance dopamine signaling and potentiate reinstatement of cocaine seeking. J Neurosci. 2013; 33:1180011810. [PubMed: 23864669]

Grundemann D, Schechinger B, Rappold GA, Schomig E. Molecular identification of the corticosterone-sensitive extra-neuronal catecholamine transporter. Nat Neurosci. 1998; 1:349-351. [PubMed: 10196521]

Grundemann D, Liebich G, Kiefer N, Koster S, Schomig E. Selective substrates for non-neuronal monoamine transporters. Mol Pharmacol. 1999; 56:1-10. [PubMed: 10385678]

Haenisch B, Bonisch H. Interaction of the human plasma membrane monoamine transporter (hPMAT) with antidepressants and antipsychotics. Naunyn Schmiedebergs Arch Pharmacol. 2010; 381:3339. [PubMed: 20012264]

Hara Y, Yakovleva T, Bakalkin G, Pickel VM. Dopamine D1 receptors have subcellular distributions conducive to interactions with prodynorphin in the rat nucleus accumbens shell. Synapse. 2006; 60:1-19. [PubMed: 16575853]

Hill JE, Gasser PJ. Organic cation transporter 3 is densely expressed in the intercalated cell groups of the amygdala: anatomical evidence for a stress hormone-sensitive dopamine clearance system. $\mathrm{J}$ Chem Neuroanat. 2013; 52:36-43. [PubMed: 23694905]

Hill JE, Makky K, Shrestha L, Hillard CJ, Gasser PJ. Natural and synthetic corticosteroids inhibit uptake 2-mediated transport in CNS neurons. Physiol Behav. 2011; 104:306-311. [PubMed: 21081135] 
Horvath G, Wanner A. Molecular targets for steroids in airway vascular smooth muscle. Arch Physiol Biochem. 2003; 111:341-344. [PubMed: 15764070]

Horvath G, Sutto Z, Torbati A, Conner GE, Salathe M, Wanner A. norepinephrine transport by the extraneuronal mono-amine transporter in human bronchial arterial smooth muscle cells. Am J Physiol Lung Cell Mol Physiol. 2003; 285:829-837.

Inazu M, Takeda H, Ikoshi H, Sugisawa M, Uchida Y, Matsumiya T. Pharmacological characterization and visualization of the glial serotonin transporter. Neurochem Int. 2001; 39:39-49. [PubMed: 11311448]

Inazu M, Takeda H, Matsumiya T. Expression and functional characterization of the extraneuronal monoamine transporter in normal human astrocytes. J Neurochem. 2003a; 84:43-52. [PubMed: 12485400]

Inazu M, Takeda H, Matsumiya T. Functional expression of the norepinephrine transporter in cultured rat astrocytes. J Neurochem. 2003b; 84:136-144. [PubMed: 12485410]

Jayanthi LD, Ramamoorthy S. Regulation of monoamine transporters: influence of psychostimulants and therapeutic antidepressants. AAPS J. 2005; 7:E728-E738. [PubMed: 16353949]

Jiang X, Chen A, Li H. Histaminergic modulation of excitatory synaptic transmission in the rat basolateral amygdala. Neuro-science. 2005; 131:691-703.

Jiang X, Xing G, Yang C, Verma A, Zhang L, Li H. Stress impairs 5-HT2A receptor-mediated serotonergic facilitation of GABA release in juvenile rat basolateral amygdala. Neuropsychopharmacology. 2009; 34:410-423. [PubMed: 18536707]

Karhunen T, Tilgmann C, Ulmanen I, Panula P. Catechol-O-methyltransferase (COMT) in rat brain: immunoelectron microscopic study with an antiserum against rat recombinant COMT protein. Neurosci Lett. 1995; 187:57-60. [PubMed: 7617303]

Konstandi M, Johnson E, Lang MA, Malamas M, Marselos M. Noradrenaline, dopamine, serotonin: different effects of psychological stress on brain biogenic amines in mice and rats. Pharmacol Res. 2000; 41:341-346. [PubMed: 10675287]

Li R, Nishijo H, Ono T, Ohtani Y, Ohtani O. Synapses on GABAergic neurons in the basolateral nucleus of the rat amygdala: double-labeling immunoelectron microscopy. Synapse. 2002; 43:4250. [PubMed: 11746732]

Lips KS, Volk C, Schmitt BM, Pfeil U, Arndt P, Miska D, Ermert L, Kummer W, Koepsell H. Polyspecific cation transporters mediate luminal release of acetylcholine from bronchial epithelium. Am J Respir Cell Mol Biol. 2005; 33:79-88. [PubMed: 15817714]

McDonald AJ, Mascagni F. Neuronal localization of 5-HT type 2A receptor immunoreactivity in the rat basolateral amygdala. Neuroscience. 2007; 146(1):306-320. [PubMed: 17331657]

McReynolds JR, Donowho K, Abdi A, McGaugh JL, Roozendaal B, McIntyre CK. Memoryenhancing corticosterone treatment increases amygdala norepinephrine and Arc protein expression in hippocampal synaptic fractions. Neurobiol Learn Mem. 2010; 93(3):312-321. [PubMed: 19932757]

Moron JA, Brockington A, Wise RA, Rocha BA, Hope BT. Dopamine uptake through the norepinephrine transporter in brain regions with low levels of the dopamine transporter: evidence from knock-out mouse lines. J Neurosci. 2002; 22:389-395. [PubMed: 11784783]

Muller J, Da LC. Ultracytochemical demonstration of monoamine oxidase activity in nervous and nonnervous tissue of the rat. J Histochem Cytochem. 1977; 25:337-348. [PubMed: 864237]

Muller JF, Mascagni F, McDonald AJ. Pyramidal cells of the rat basolateral amygdala: synaptology and innervation by parvalbumin-immunoreactive interneurons. J Comp Neurol. 2006; 494:635650. [PubMed: 16374802]

Muller JF, Mascagni F, McDonald AJ. Dopaminergic innervation of pyramidal cells in the rat basolateral amygdala. Brain Struct Funct. 2009; 213:275-288. [PubMed: 18839210]

Myohanen TT, Schendzielorz N, Mannisto PT. Distribution of catechol-O-methyltransferase (COMT) proteins and enzymatic activities in wild-type and soluble COMT deficient mice. J Neurochem. 2010; 113:1632-1643. [PubMed: 20374420]

Nemeroff CB, Owens MJ. Pharmacologic differences among the SSRIs: focus on monoamine transporters and the HPA axis. CNS Spectr. 2004; 9:23-31. [PubMed: 15181382] 
Paxinos, G., Watson, C. The Rat Brain in Stereotaxic Coordinates. 4th. San Diego: Academic Press; 1998.

Peters, A., Palay, SL., Webster, H. The Fine Structure of the Nervous System. New York: Oxford University Press; 1991.

Pinard CR, Muller JF, Mascagni F, McDonald AJ. Dopaminergic innervation of interneurons in the rat basolateral amygdala. Neuroscience. 2008; 157:850-863. [PubMed: 18948174]

Pinard CR, Mascagni F, Muller JF, McDonald AJ. Limited convergence of rhinal cortical and dopaminergic inputs in the rat basolateral amygdala: an ultrastructural analysis. Brain Res. 2010; 1332:48-56. [PubMed: 20346351]

Pinto A, Sesack SR. Ultrastructural analysis of prefrontal cortical inputs to the rat amygdala: spatial relationships to presumed dopamine axons and D1 and D2 receptors. Brain Struct Funct. 2008; 213(1-2):159-175. [PubMed: 18340460]

Rice ME, Cragg SJ. Dopamine spillover after quantal release: rethinking dopamine transmission in the nigrostriatal pathway. Brain Res Rev. 2008; 58:303-313. [PubMed: 18433875]

Roozendaal B, Hahn EL, Nathan SV, de Quervain DJ, McGaugh JL. Glucocorticoid effects on memory retrieval require concurrent noradrenergic activity in the hippocampus and basolateral amygdala. $\mathrm{J}$ Neurosci. 2004; 24:8161-8169. [PubMed: 15371517]

Roozendaal B, Hui GK, Hui IR, Berlau DJ, McGaugh JL, Weinberger NM. Basolateral amygdala noradrenergic activity mediates corticosterone-induced enhancement of auditory fear conditioning. Neurobiol Learn Mem. 2006a; 86:249-255. [PubMed: 16630730]

Roozendaal B, Okuda S, Van der Zee EA, McGaugh JL. Glucocorticoid enhancement of memory requires arousal-induced noradrenergic activation in the basolateral amygdala. Proc Natl Acad Sci USA. 2006b; 103:6741-6746. [PubMed: 16611726]

Rosenkranz JA, Grace AA. Cellular mechanisms of infralimbic and prelimbic prefrontal cortical inhibition and dopaminergic modulation of basolateral amygdala neurons in vivo. J Neurosci. 2002; 22:324-337. [PubMed: 11756516]

Schomig E, Lazar A, Grundemann D. Extraneuronal monoamine transporter and organic cation transporters 1 and 2: a review of transport efficiency. Handb Exp Pharmacol. 2006; 175:151-180.

Streich S, Bruss M, Bonisch H. Expression of the extraneuronal monoamine transporter (uptake2) in human glioma cells. Naunyn Schmiedebergs Arch Pharmacol. 1996; 353:328-333. [PubMed: 8692289]

Stutzmann GE, McEwen BS, Ledoux JE. Serotonin modulation of sensory inputs to the lateral amygdala: dependency on corticosterone. J Neurosci. 1998; 18:9529-9538. [PubMed: 9801389]

Takeda H, Inazu M, Matsumiya T. Astroglial dopamine transport is mediated by norepinephrine transporter. Naunyn Schmiedebergs Arch Pharmacol. 2002; 366:620-623. [PubMed: 12444505]

Trendelenburg $\mathrm{U}$. The interaction of transport mechanisms and intracellular enzymes in metabolizing systems. J Neural Transm Suppl. 1990; 32:3-18.

Ulmanen I, Peranen J, Tenhunen J, Tilgmann C, Karhunen T, Panula P, Bernasconi L, Aubry JP, Lundstrom K. Expression and intracellular localization of catechol O-methyltransferase in transfected mammalian cells. Eur J Biochem. 1997; 243:452-459. [PubMed: 9030772]

Verhaagh S, Barlow DP, Zwart R. The extraneuronal monoamine transporter Slc22a3/Orct3 colocalizes with the Maoa metabolizing enzyme in mouse placenta. Mech Dev. 2001; 100:127-130. [PubMed: 11118898]

Vialou V, Amphoux A, Zwart R, Giros B, Gautron S. Organic cation transporter 3 (Slc22a3) is implicated in salt-intake regulation. J Neurosci. 2004; 24:2846-2851. [PubMed: 15028779]

Vialou V, Balasse L, Callebert J, Launay JM, Giros B, Gautron S. Altered aminergic neurotransmission in the brain of organic cation transporter 3-deficient mice. J Neurochem. 2008; 106(3):1471-1482. [PubMed: 18513366]

Wang H, Cuzon VC, Pickel VM. Ultrastructural localization of delta-opioid receptors in the rat caudate-putamen nucleus during postnatal development: relation to synaptogenesis. J Comp Neurol. 2003; 467:343-353. [PubMed: 14608598]

Wu SC, O'Connell TD. Nuclear compartmentalization of alpha1-adrenergic receptor signaling in adult cardiac myocytes. J Cardiovasc Pharmacol. 2015; 65:91-100. [PubMed: 25264754] 
Wu SC, Dahl EF, Wright CD, Cypher AL, Healy CL, O'Connell TD. Nuclear localization of a1Aadrenergic receptors is required for signaling in cardiac myocytes: an "inside-out" a1-AR signaling pathway. J Am Heart Assoc. 2014; 3:e000145. [PubMed: 24772522]

Wultsch T, Grimberg G, Schmitt A, Painsipp E, Wetzstein H, Breitenkamp AF, Grundemann D, Schomig E, Lesch KP, Gerlach M, Reif A. Decreased anxiety in mice lacking the organic cation transporter 3. J Neural Transm. 2009; 116(6):689-697. [PubMed: 19280114]

Yoshikawa T, Naganuma F, Iida T, Nakamura T, Harada R, Mohsen AS, Kasajima A, Sasano H, Yanai K. Molecular mechanism of histamine clearance by primary human astrocytes. Glia. 2013; 61:905-916. [PubMed: 23505051]

Zhang J, Muller JF, McDonald AJ. Noradrenergic innervation of pyramidal cells in the rat basolateral amygdala. Neuroscience. 2013; 228:395-408. [PubMed: 23103792] 

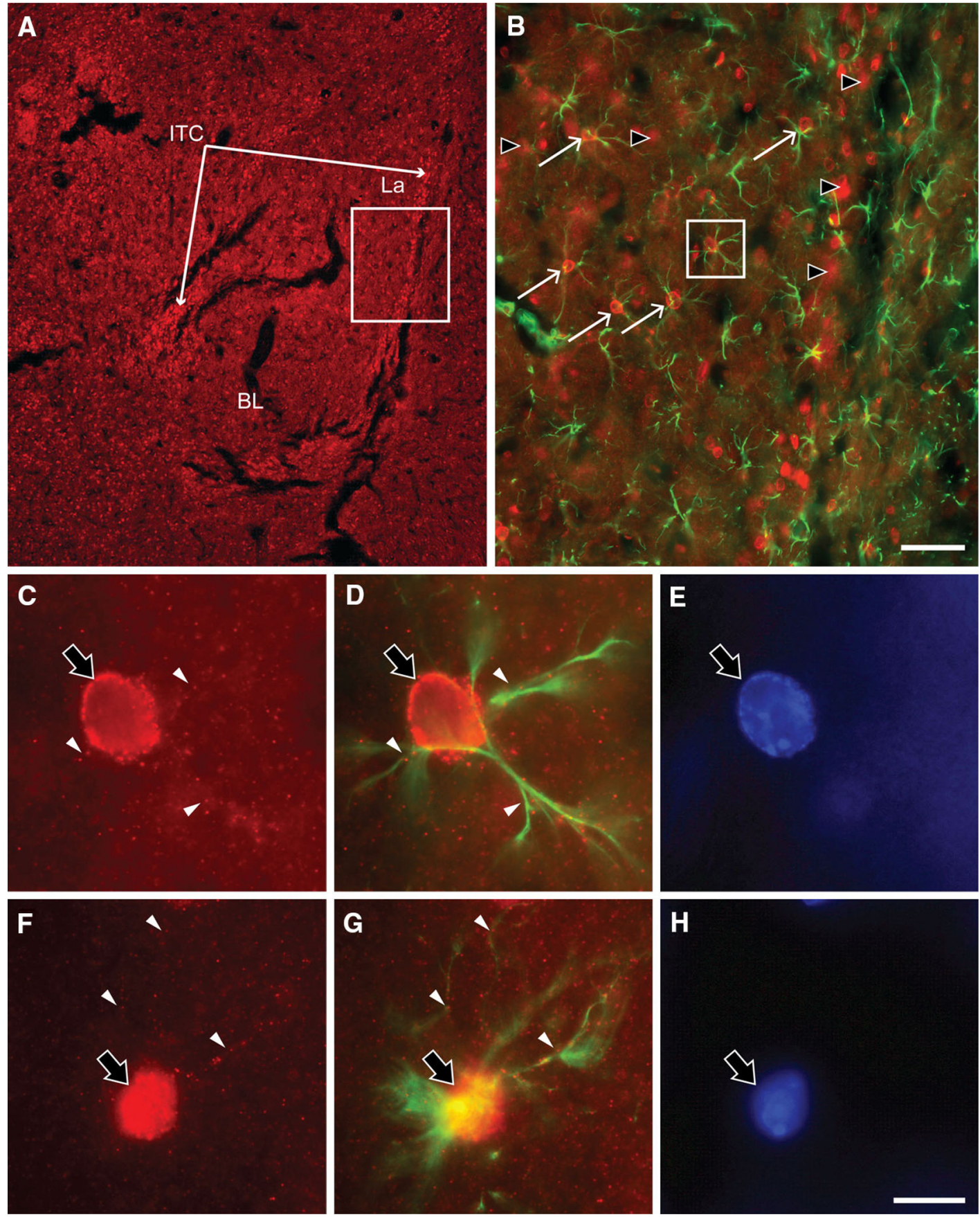

Fig. 1.

Fluorescence photomicrographs depicting OCT3 (red) and GFAP (green) immunoreactivity in coronal sections of the rat (a-e) and mouse (f-h) amygdala. OCT3-immunoreactive perikarya and punctae are observed throughout the amygdala, with particularly high density in the intercalated cell masses (a). b Dense OCT3 immunoreactivity is localized around apparent cell nuclei, including both GFAP-positive, and GFAP-negative cells. c, d, f, $\mathbf{g}$ Dense OCT3 immunolabeling is observed surrounding a glial nucleus, and punctate OCT3 immunoreactivity is observed in the surrounding area, including in apparent glial processes 
(white arrowheads). $\mathbf{e , ~} \mathbf{h}$ DAPI staining of the nucleus of the cells in $\mathbf{c}, \mathbf{d}$ and $\mathbf{f}, \mathbf{g}$, respectively. $B L$ basolateral amygdaloid nucleus, ITC intercalated cell clusters, $L a$ lateral amygdaloid nucleus. Scale bar $200 \mu \mathrm{m}$ (a), $50 \mu \mathrm{m}$ (b), $10 \mu \mathrm{m}$ (c-h) 

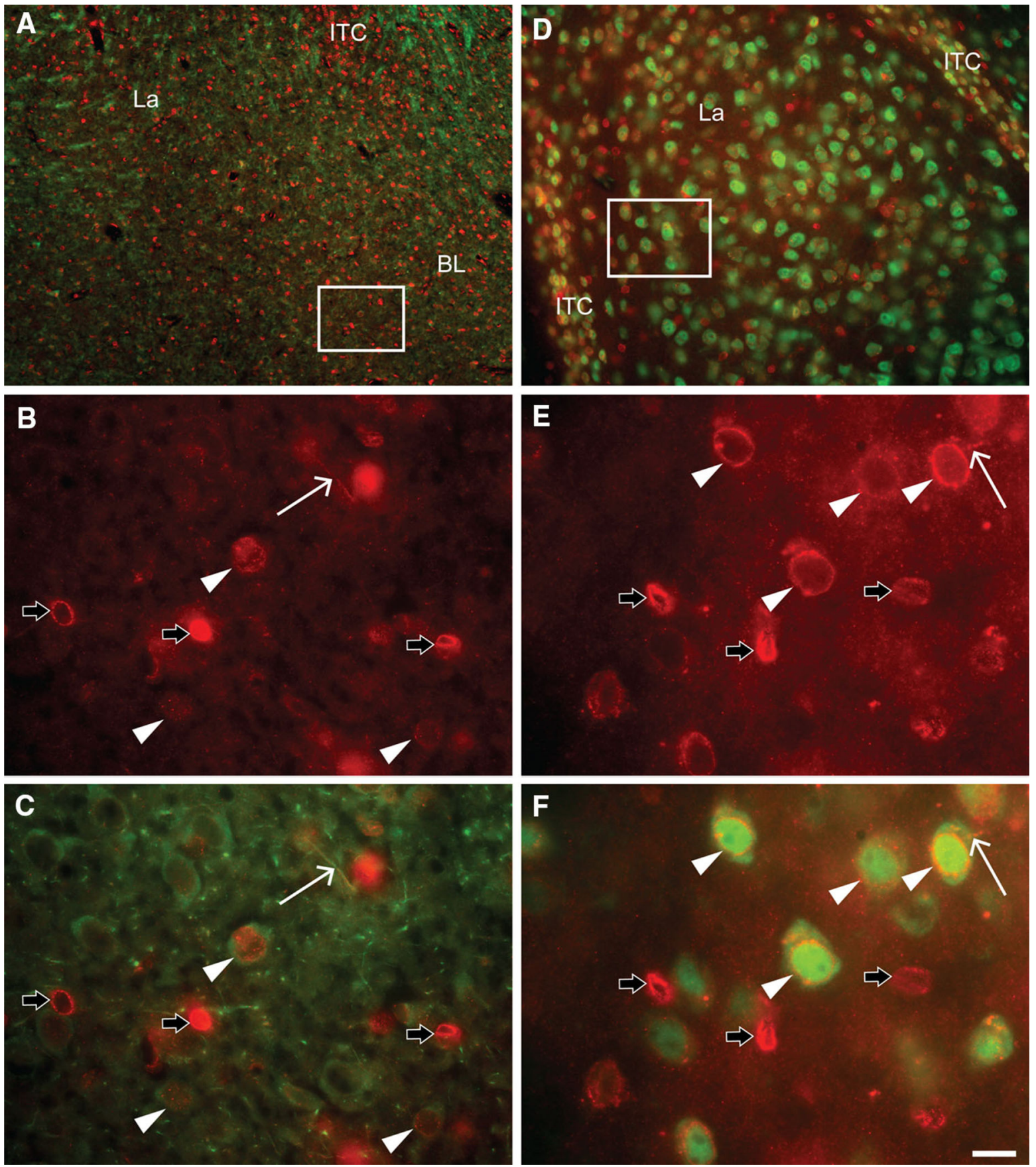

Fig. 2.

Fluorescence photomicrographs of coronal sections dual-labeled with OCT3 (red) and neuron-specific proteins ( green) in coronal sections of the rat (a-c) and mouse $(\mathbf{d}-\mathbf{f})$ amygdala. Neuron-specific markers are $\beta$-III tubulin (a-c) or NeuN $(\mathbf{d}-\mathbf{f})$. Boxes in $(\mathbf{a})$ and (d) indicate regions shown at higher magnification in $\mathbf{b}, \mathbf{c}$, and $\mathbf{e}, \mathbf{f}$, respectively. a OCT3immunoreactive cell nuclei and punctae (red) are apparent throughout the amygdala, with particularly high density in the intercalated cell masses. In b and c, OCT3 immunoreactivity is densely localized around apparent nuclei of non-neuronal ( $\beta$-III tubulin-negative) cells 
(black arrows) and less densely localized around nuclei of $\beta$-III tubulin-positive cells (white arrowheads). Punctate OCT3 immunoreactivity is observed in surrounding areas, including in $\beta$-III tubulin-immunoreactive processes (white arrows). OCT3-immunoreactive nuclei are observed in both $\beta$-III tubulin-immunoreactive (white arrowheads) and -immunonegative (black arrows) perikarya. d-f OCT3-immunoreactive cell nuclei and punctae (red) are apparent throughout the amygdala. In e and $\mathbf{f}$, dense OCT3 immunoreactivity is localized around cell nuclei (white arrowheads and black arrows). In f, OCT3-immunoreactive nuclei are observed in both NeuN-immunopositive (white arrowheads) and -immunonegative (black arrows) perikarya. BL basolateral amygdaloid nucleus, ITC intercalated cell clusters, La lateral amygdaloid nucleus. Scale bar $100 \mu \mathrm{m}(\mathbf{a}) ; 50 \mu \mathrm{m}(\mathbf{d}) ; 16.7 \mu \mathrm{m}(\mathbf{b}-\mathbf{e})$ 

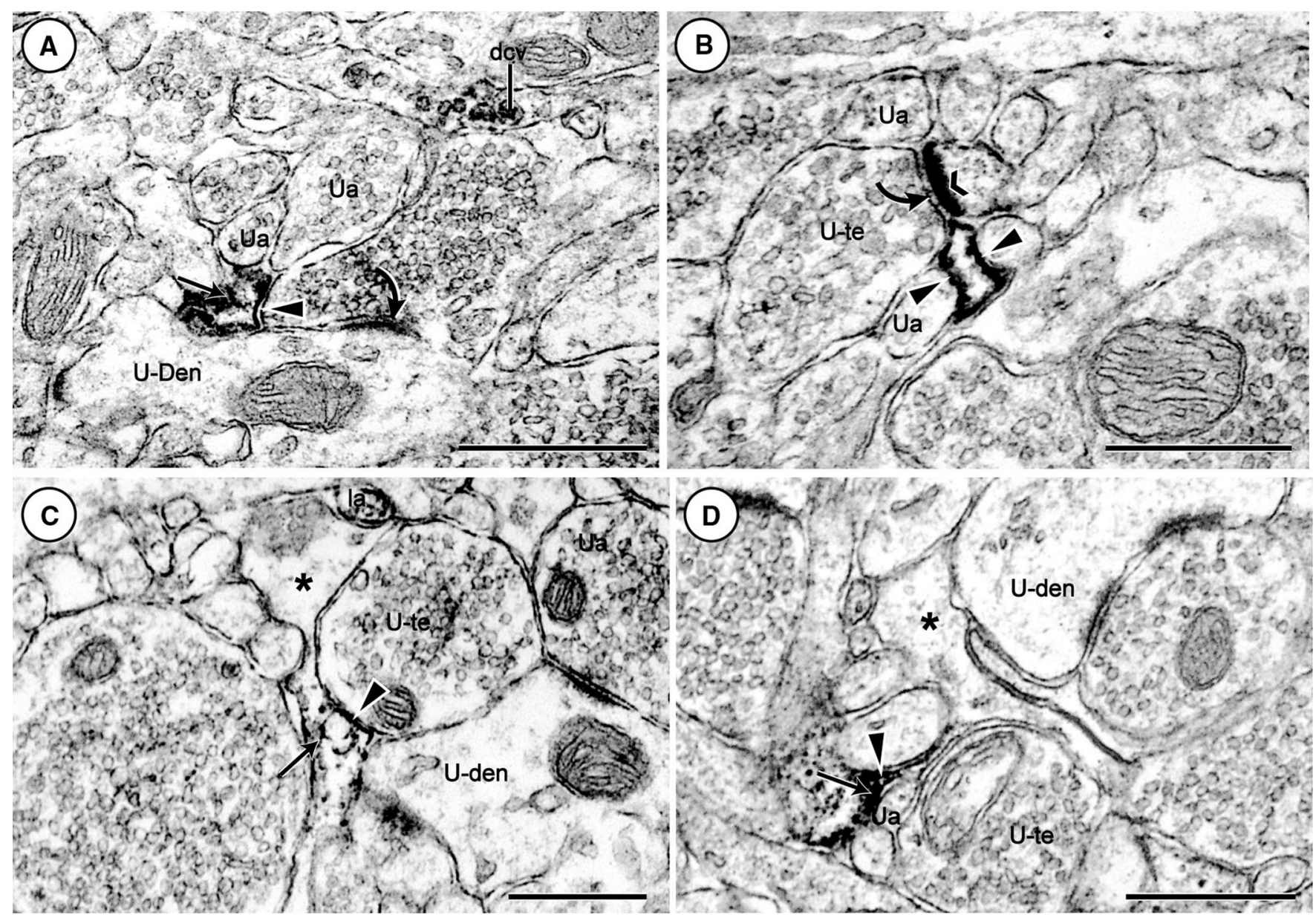

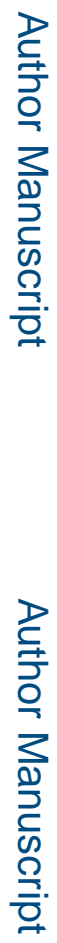

Fig. 3.

Electron microscopic images showing black precipitous immunoperoxidase reaction product identifying OCT3 immunoreactivity in glial processes in the rat (a-c), and mouse (d) BLA.

The OCT3 labeling is densely distributed on plasma membranes (arrowheads) and within the cytoplasm (thin arrows) of filamentous glial processes imposed at asymmetric axodendritic synapses (curved arrows in $\mathbf{a}$ and $\mathbf{b}$ ) and opposed to unlabeled axon terminals ( $U$-te) and small axons ( $U a$ ) without recognizable synaptic specializations in $\mathbf{c}$ and $\mathbf{d}$, respectively. OCT3 immunoperoxidase labeling is also localized to large dense core vesicles $(\mathrm{dcv})$ in a longitudinally cut axon in a, the postsynaptic membrane (chevron) in a dendritic spine receiving an asymmetric (curved arrow) from an unlabeled axon terminal in $\mathbf{b}$, and a small axon (la) in c. dcv dense core vesicle, $U a$ unlabeled axon, $U$-Den unlabeled dendrite, $U$-te unlabeled terminal; *unlabeled glial profile. Scale bars $500 \mathrm{~nm}$ 


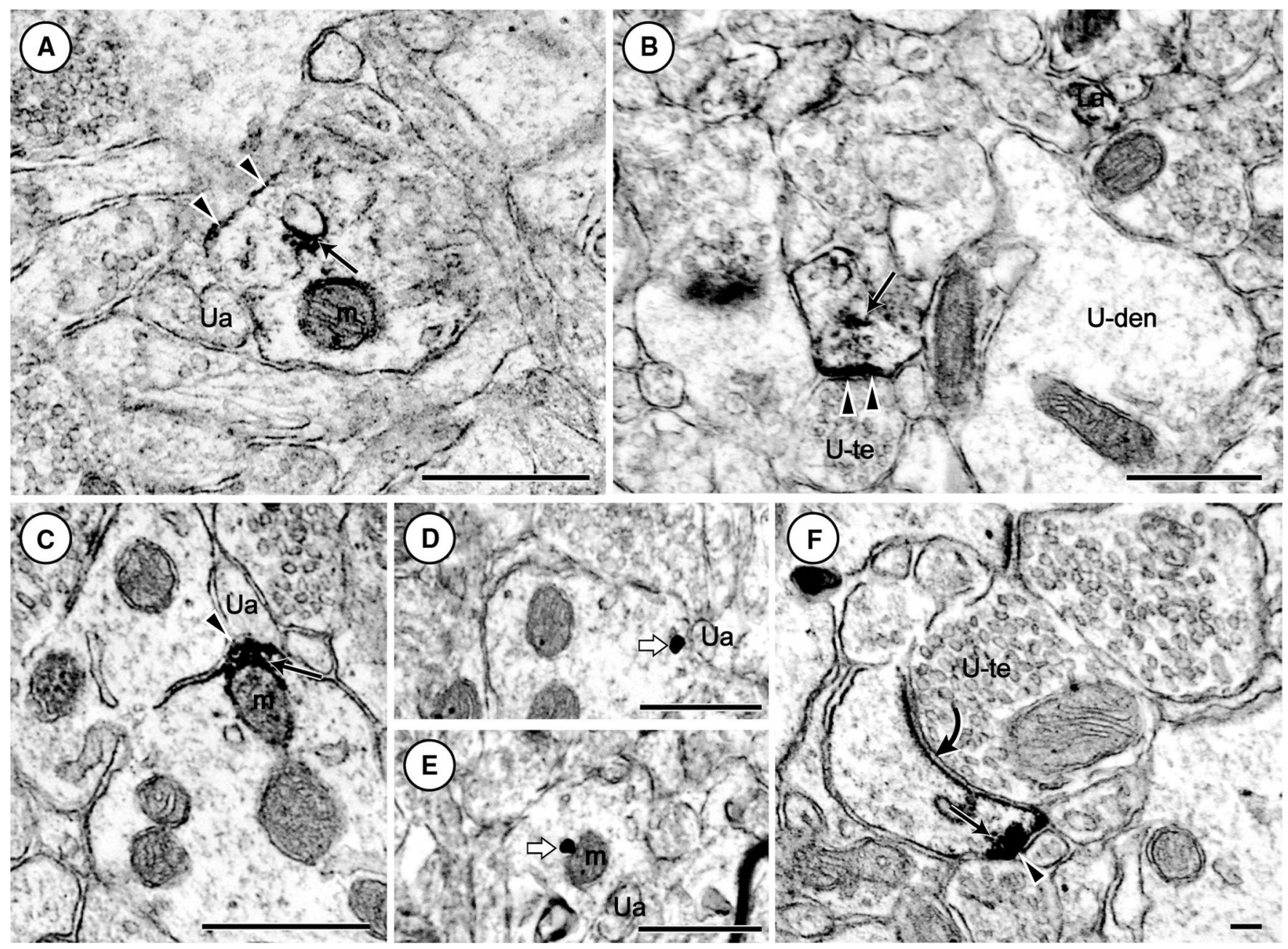

Fig. 4.

Electron microscopic images showing immunolabeling for OCT3 in dendritic profiles in the rat $(\mathbf{a}, \mathbf{b})$ and mouse (c-f) BLA. Immunoperoxidase labeling in $\mathbf{a}-\mathbf{c}$ is seen as a precipitous reaction product localized to discrete segments of the plasma membrane (arrowheads), nearby endomembranes (thin arrows), and/or surfaces of mitochondria $(\mathrm{m})$ in both species. The immunoperoxidase surface labeling is opposed by unlabeled axons ( $\mathrm{Ha}$ ) and axon terminals $(U-T e)$ without defined synaptic junctions. In $\mathbf{d}$ and $\mathbf{e}$, the dendritic surface and mitochondrial distribution, respectively, of OCT3 is revealed by immunogold-silver deposits (block arrows). In f, OCT3-immunoperoxidase labeling (arrowhead) is localized to the lateral surface of a spine head that receives an asymmetric synapse (curved arrow) from an unlabeled axon terminal. Labeled axons $(L a)$ and unlabeled dendrites $(U-D e n)$ are also seen in the neuropil. Scale bar $500 \mathrm{~nm}$ in $\mathbf{a}-\mathbf{c}$ and $100 \mathrm{~nm}$ in $\mathbf{f}$ 


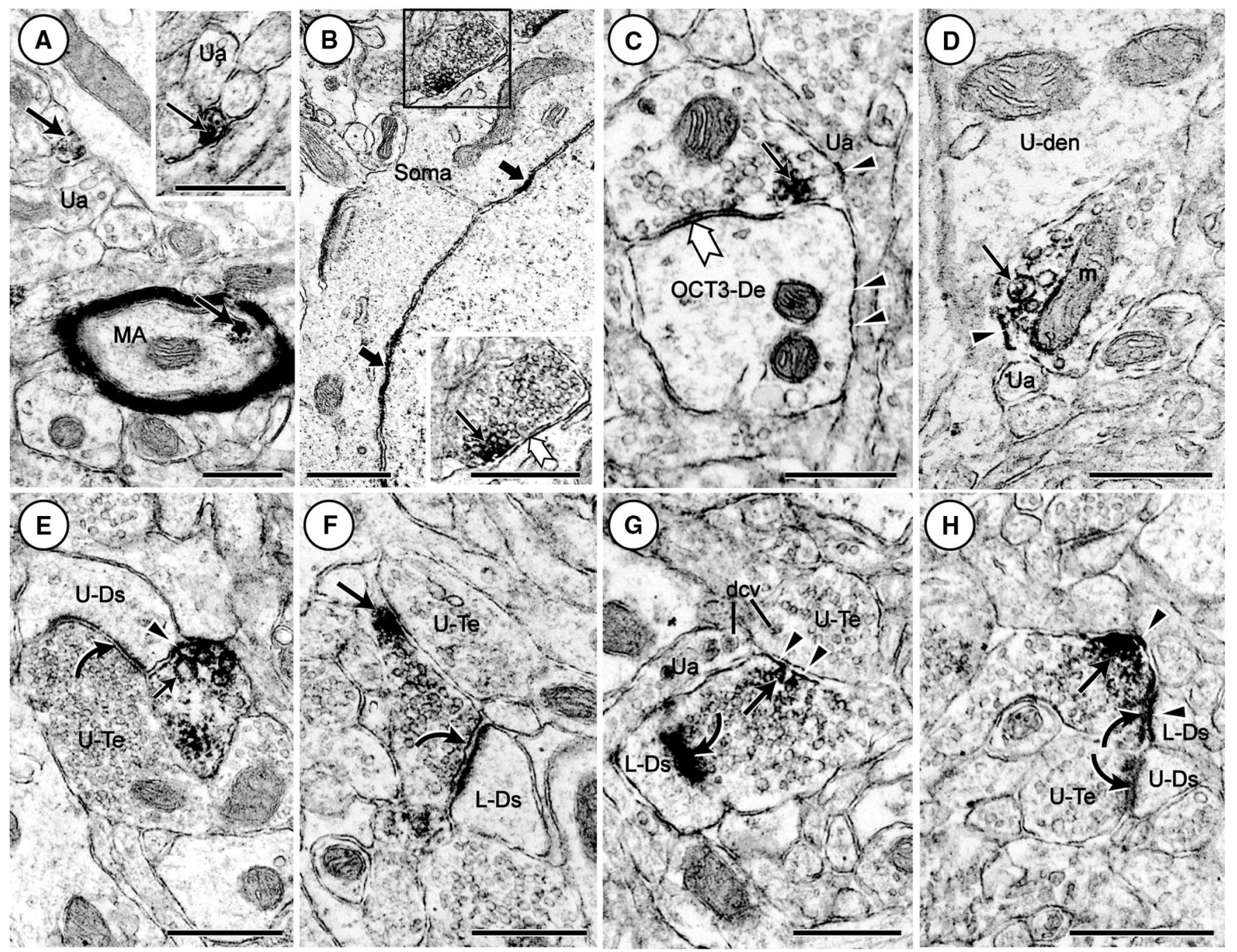

Fig. 5.

Electron microscopic images showing immunoperoxidase labeling for OCT3 in axonal profiles in the rat (a-g) and mouse (h) BLA. The OCT immunoperoxidase reaction product is seen around vesicular organelles (thin arrows) and along selected segments of the axonal and dendritic plasma membrane (arrowheads) in both species. In a, OCT3 labeling in seen in small unmyelinated axons located in bundles of unlabeled axons ( $\mathrm{Ua}$ ) and in a nearby myelinated axon $(M A)$. In $\mathbf{b}$ and $\mathbf{c}$, respectively, the immunoreactive terminals form symmetric synapses (white arrow) with a soma showing intermittent peroxidase labeling along the nuclear membrane (black block arrow) and a dendrite (OCT3-De) showing plasmalemmal (arrowheads) labeling. The boxed region of the axonal contact is shown at higher magnification in the inset in the lower right corner of $\mathbf{b}$. In $\mathbf{d}$ and $\mathbf{e}$, the OCT3 immunoreactive axon terminals are without defined synaptic junctions, and oppose an unlabeled dendrite ( $U$-den) and dendritic spine ( $U-D S$ ), respectively. In $\mathbf{f}-\mathbf{h}$, the OCT3labeled terminals form asymmetric synapses (curved arrows) with dendritic spines that are OCT-3 labeled ( $L-D s)$ or unlabeled ( $U-D s)$. $d c v$ dense core vesicle, $L-D s$ labeled dendritic 
spine, $m$ mitochondrion, $M A$ myelinated axon, OCT3-De OCT3-labeled dendrite, $U a$ unlabeled axon, $U$-Den unlabeled dendrite, $U$-Te unlabeled terminal. Scale bars $500 \mathrm{~nm}$ 

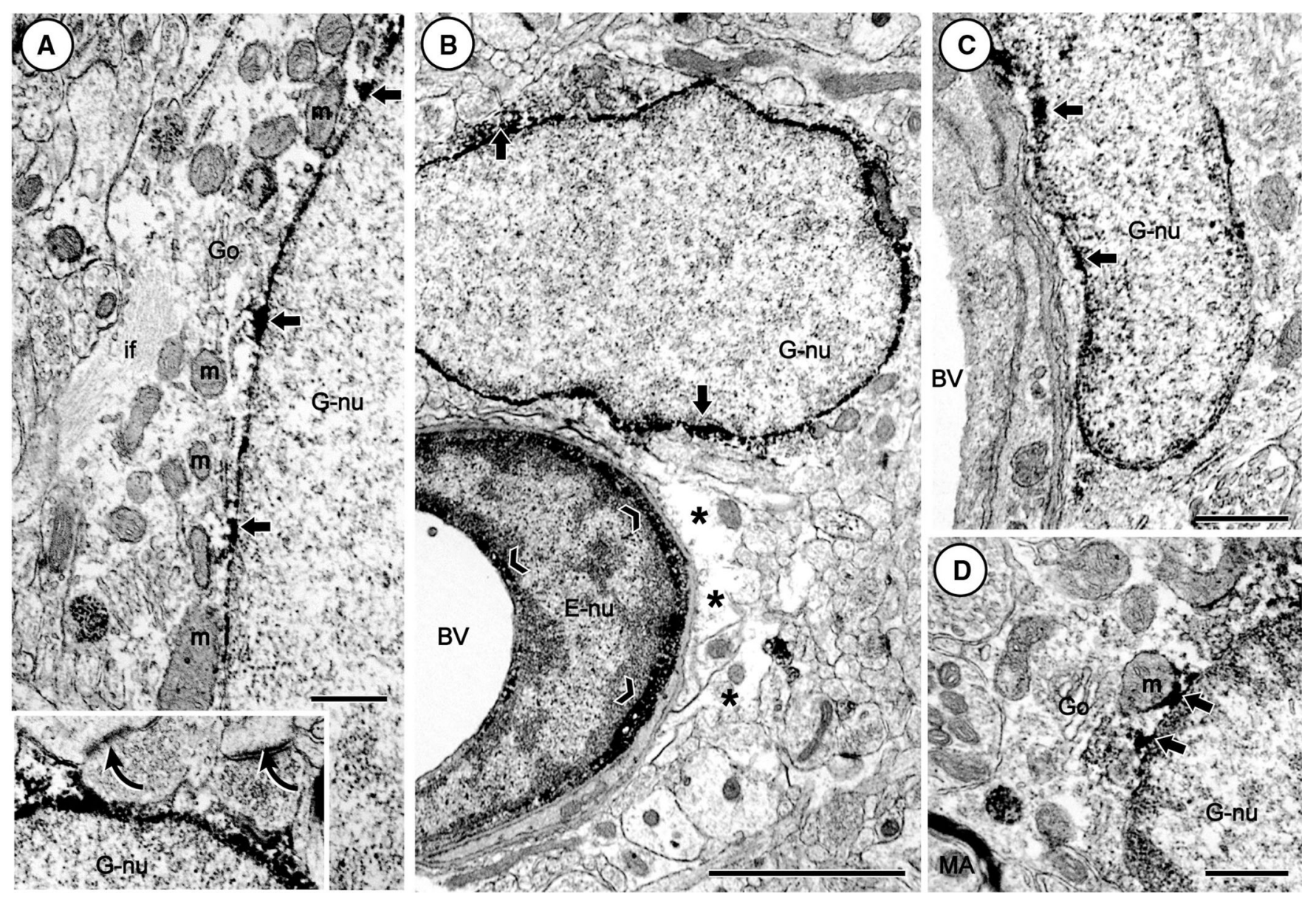

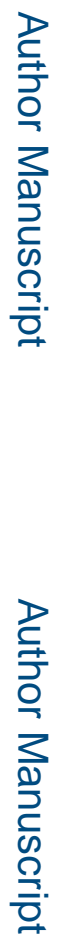

Fig. 6.

Electron microscopic images showing immunoperoxidase labeling of OCT3 in glial cells in the rat $(\mathbf{a}, \mathbf{b})$ and mouse $(\mathbf{c}, \mathbf{d})$ BLA. The OCT3 immunoreactivity is unevenly distributed and often aggregated (block arrows) on portions of the limiting membrane of glial nuclei ( $G$ $n u$ ) in both species. These aggregates are located in close proximity and sometimes in direct contact with membranes of mitochondria $(m)$ near the Golgi lamellae $(G o)$ in astrocytic (a) and non-astrocytic (b-d) glia that are morphologically distinguished by their respective (1) bundles of intermediate filaments (if) and (2) dense rim of chromatin beneath the nuclear membrane. Inset in a shows cytoplasmic and nuclear OCT3 labeling in an apical portion of the astrocyte enclosing two unlabeled axon terminals that form asymmetric axodendritic synapses (curved arrows). In $\mathbf{b}$ and $\mathbf{c}$, the OCT3-labeled glial cells are located near blood vessels $(B V)$. In $\mathbf{b}$, OCT3 immunoreactivity (chevron) is also seen in the cytoplasmic, but not in nuclear $(E-n u)$ compartments of the endothelial cell. Astrocytic end feet (asterisk) on the $\mathrm{BV}$ in $\mathrm{B}$ and a myelinated axon $(M A)$ in $\mathbf{d}$ are without immunolabeling. $B V$ blood vessel, $G$-nu glial nucleus, $G o$ Golgi apparatus, $E$-nu endothelial cell nucleus, if intermediate filaments, $m$ mitochondrion, $M A$ myelinated axon. Scale bar $500 \mathrm{~nm}$ in a, $\mathbf{c}$ and $2 \mu \mathrm{m}$ in inset of $\mathbf{a}$ 


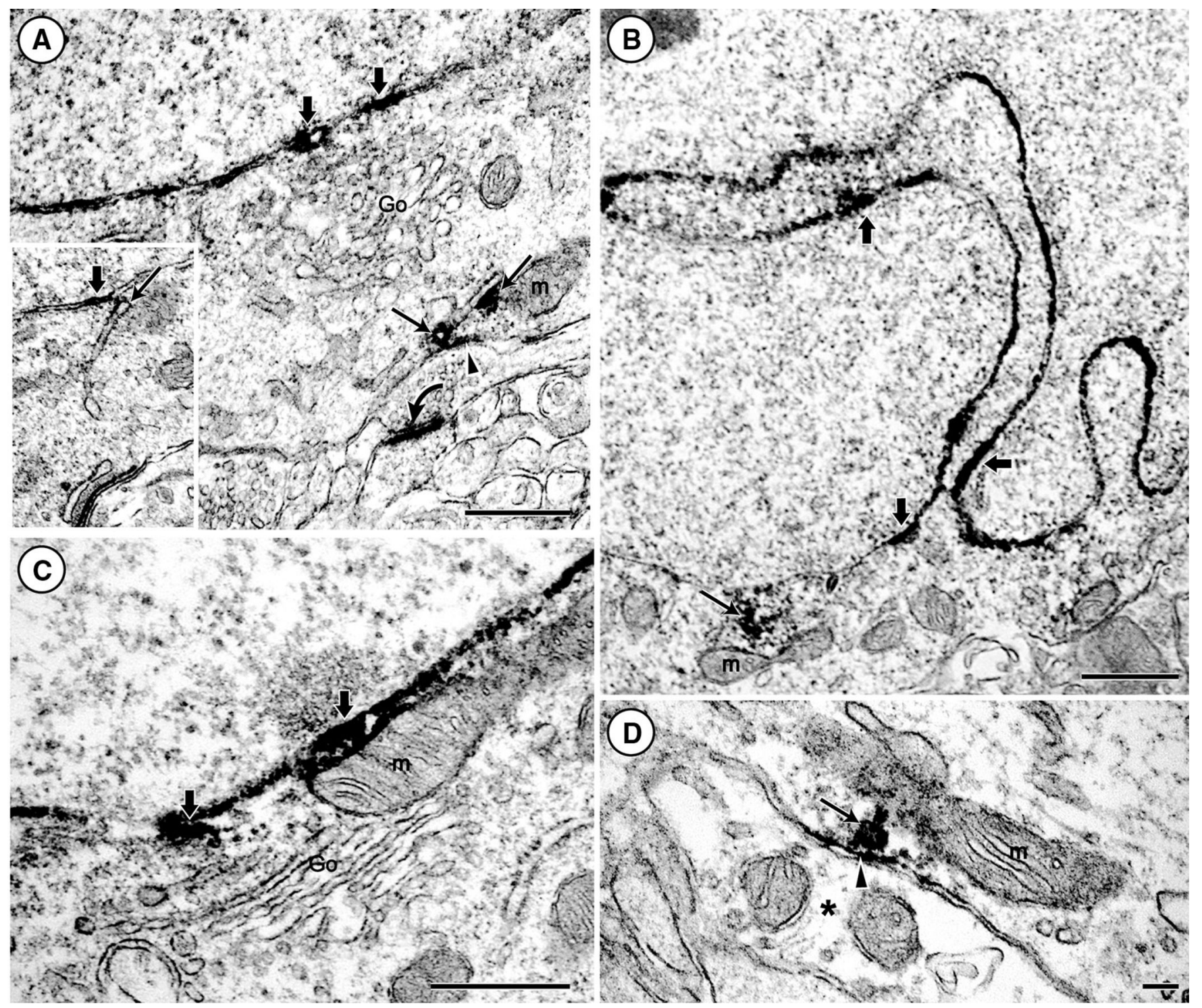

Fig. 7.

Electron microscopic images showing immunoperoxidase labeling for OCT3 in somatodendritic profiles in the rat $(\mathbf{a}, \mathbf{c}, \mathbf{d})$ and mouse (b) BLA. The peroxidase reaction product (block arrows) is unevenly distributed along a round unindented $(\mathbf{a}, \mathbf{c})$ and a heavily indented (b) nuclear membrane in somata that also show plasmalemmal (arrow head) and endomembrane (thin arrows) distributions of OCT3 immunoreactivity near a mitochondrion $(m)$ in $\mathbf{a}$ and $\mathbf{b}$. The immunolabeled soma in $\mathbf{a}$ is opposed to an unlabeled axon terminal forming an asymmetric axospinous synapse (curved arrow in a). In d, the OCT3 plasmalemmal labeling (arrowhead) is located in a proximal dendrite that is opposed by an unlabeled astrocytic process (asterisk). In this dendritic profile, the peroxidase reaction product (thin arrow) is also distributed along a vesicle-like cytoplasmic organelle located between the plasma membrane and a nearby mitochondrion $(m)$. Go Golgi apparatus, $m$ mitochondrion, Nuc nucleolus. Scale bar $500 \mathrm{~nm}$ in a-c and $100 \mathrm{~nm}$ in d 

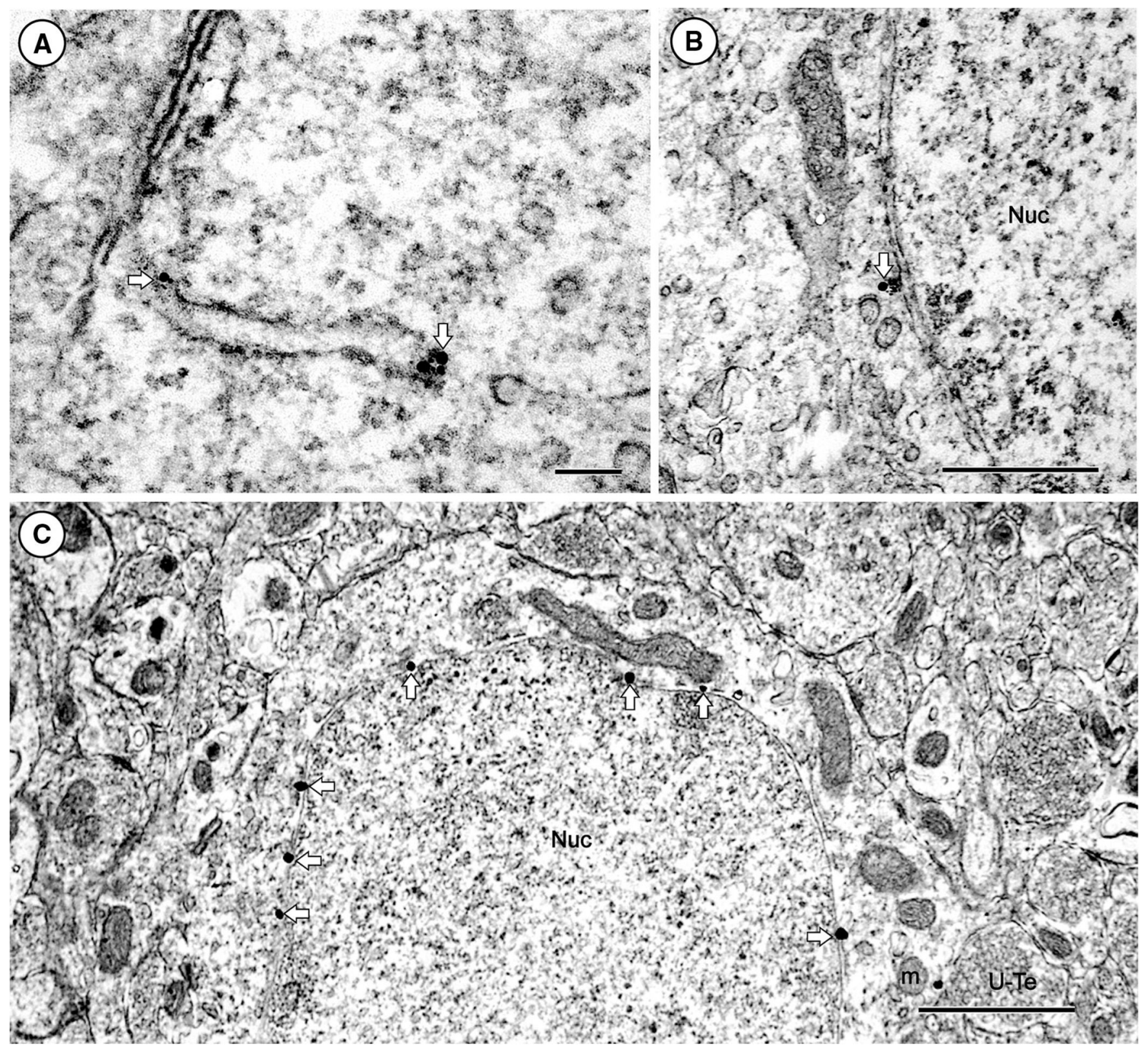

Fig. 8.

Electron microscopic images showing immunogold labeling for OCT3 in somatic profiles in the rat $(\mathbf{a}, \mathbf{b})$ and mouse (c) BLA. Gold-silver deposits (block arrows) are localized to an endomembrane beneath the plasma membrane in $\mathbf{a}$ and to the outer nuclear envelope near vesicular organelles in $\mathbf{b}$. In $\mathbf{c}$, individual gold particles (block arrows) are distributed along the entire length of the outer nuclear membrane. These particles are absent from the cytoplasm except for one gold particle that is seen near a mitochondrion $(m)$ in a portion of the soma contacted by an unlabeled axon terminal $(U-T e)$. Go Golgi apparatus, $m$ mitochondrion, Nuc nucleus, $U$-Te unlabeled terminal. Scale bar $100 \mathrm{~nm}$ in a and $500 \mathrm{~nm}$ in $\mathbf{b}$ and $\mathbf{c}$ 


\section{Table 1}

Percentage of OCT3-labeled processes in the rat and mouse BLA

\begin{tabular}{lllll}
\hline & Glial processes $(\boldsymbol{\%})$ & $\begin{array}{l}\text { Dendritic shafts and spines } \\
(\boldsymbol{\%})\end{array}$ & $\begin{array}{l}\text { Axons and axon terminals } \\
(\boldsymbol{\%})\end{array}$ & Unidentifiable processes (\%) \\
\hline Rat $n=551^{*}$ & 11.4 & 22.9 & 63.5 & 2.2 \\
Mouse $n=988^{* *}$ & 13.3 & 26.0 & 58.5 & 2.2 \\
\hline
\end{tabular}

Immunolabeling for OCT3 in glial, neuronal, and unidentified glial and/or neuronal processes within the rat and mouse BLA. The neuronal profiles are separately defined as postsynaptic dendritic (shafts and spines) and presynaptic (axons and axon terminals) compartments. OCT3-

immunolabeled structures in each category are given as a percentage of the total OCT3-labeled profiles detected in a square micron tissue area $* n$ and $* * n$ for rat and mouse, respectively

$n=$ number of labeled profiles in $3200 \mu \mathrm{m}^{2}$ tissue from 3 rats

$n=$ number of labeled profiles in $4088 \mu \mathrm{m}^{2}$ tissue from 2 mice 